OPEN ACCESS

Edited by:

Jong H. Kim

United States Department of Agriculture, Agricultural Research Service, United States

Reviewed by:

Valeria Scala,

Centro di Ricerca Difesa e Sperimentazione (CREA-DC), Italy Claudio Altomare,

National Research Council (CNR), Italy

*Correspondence: Larisa Shcherbakova larisavniif@yahoo.com

Vitaly Dzhavakhiya dzhavakhiya@yahoo.com

Specialty section: This article was submitted to Antimicrobials, Resistance and Chemotherapy, a section of the journal

Frontiers in Microbiology

Received: 14 November 2020 Accepted: 03 February 2021

Published: 25 February 2021

Citation:

Shcherbakova L, Mikityuk O, Arslanova L, Stakheev A, Erokhin D, Zavriev S and Dzhavakhiya V (2021) Studying the Ability of Thymol to Improve Fungicidal Effects of Tebuconazole and Difenoconazole Against Some Plant Pathogenic Fung in Seed or Foliar Treatments.

Front. Microbiol. 12:629429. doi: 10.3389/fmicb.2021.629429

\section{Studying the Ability of Thymol to Improve Fungicidal Effects of Tebuconazole and Difenoconazole Against Some Plant Pathogenic Fungi in Seed or Foliar Treatments}

\author{
Larisa Shcherbakova ${ }^{1 *}$, Oleg Mikityuk ${ }^{1}$ Lenara Arslanova², Alexander Stakheev³, \\ Denis Erokhin², Sergey Zavriev ${ }^{3}$ and Vitaly Dzhavakhiya2* \\ 1 Laboratory of Physiological Plant Pathology, All-Russian Research Institute of Phytopathology, Moscow, Russia, \\ ${ }^{2}$ Department of Molecular Biology, All-Russian Research Institute of Phytopathology, Moscow, Russia, ${ }^{3}$ Laboratory \\ of Molecular Diagnostics, Shemyakin-Ovchinnikov Institute of Bioorganic Chemistry, Moscow, Russia
}

Thymol, a secondary plant metabolite possessing antifungal and chemosensitizing activities, disrupts cell wall or membrane integrity and interferes with ergosterol biosynthesis. Thymol also functions as a redox-active compound inducing generation of reactive oxygen species and lipid peroxidation in fungal cells. Previously, we showed thymol significantly enhanced the in vitro growth inhibitory effect of difenoconazole against Bipolaris sorokiniana and Parastagonospora nodorum. More recently, we demonstrated a possibility to use thymol to overcome the resistance of a $P$. nodorum strain able to grow on difenoconazole-containing media. However, potential for thymol to serve as a chemosensitizing agent in seed or plant treatments, to provide an effective suppression of the above-mentioned plant pathogens by triazole fungicides applied in lowered dosages, had yet to be tested. In the work presented here, we showed combined treatments of naturally infected barley seeds with thymol and difenoconazole (Dividend ${ }^{\circledR} 030$ FS) synergistically exacerbated the protective effect against common root rot agent, B. sorokiniana, and other fungi (Fusarium spp. and Alternaria spp.). Similarly, co-applied treatment of wheat seeds, artificially inoculated with Fusarium culmorum, resulted in equivalent reduction of disease incidence on barley seedlings as application of Dividend ${ }^{\circledR}$, alone, at a ten-fold higher dosage. In foliar treatments of wheat seedlings, thymol combined with Folicur ${ }^{\circledR} 250$ EC (a.i. tebuconazole) enhanced sensitivity of $P$. nodorum, a glume/leaf blotch pathogen, to the fungicide and provided a significant mitigation of disease severity on treated seedlings, compared to controls, without increasing Folicur ${ }^{\circledast}$ dosages. Folicur ${ }^{\circledast}$ co-applied with thymol was also significantly more effective against a strain of $P$. nodorum tolerant to Folicur ${ }^{\circledR}$ alone. No additional deoxynivalenol or zearalenone production was found 
when a toxigenic $F$. culmorum was cultured in a nutrient medium containing thymol at a concentration used for chemosensitization of root rot agents. Accordingly, F. culmorum exposure to thymol at the sensitizing concentration did not up-regulate key genes associated with the biosynthesis of trichothecene or polyketide mycotoxins in this pathogen. Further studies using field trials are necessary to determine if thymol-triazole co-applications result in sensitization of seed- and foliar-associated plant pathogenic fungi, and if thymol affects production of fusarial toxins under field conditions.

Keywords: thymol, chemosensitization to agricultural fungicides, triazoles, Fusarium spp., Bipolaris sorokiniana, Parastagonospora nodorum

\section{INTRODUCTION}

Redox-active secondary metabolites of various plants attract continuing interest with regard to the diversity of their biological activity (Jacob, 2014; de Oliveira et al., 2018). Since many of these natural compounds, including thymol, possess antibacterial, antifungal, anti-insect, and other protective properties, they are used in medicine and agriculture or are continually studied for further usage in these areas (Marchese et al., 2016). For example, thymol and thymol-containing essential oils are applied as antimicrobials (Ahmad et al., 2011; Najafloo et al., 2020) and other medical preparations (Riella et al., 2012; El-Marasy et al., 2020) or are proposed as putative ecologically friendly plantprotecting fungicides (Navarro et al., 2011; González-Aguilar et al., 2013; Castillo et al., 2014) and insecticides (Park et al., 2017), as alternatives to chemical pesticides.

An important specific feature of a number of redox-active compounds rendering them as promising agents for control of various pathogenic microorganisms, including some plant pathogenic fungi, is their ability to induce oxidative stress in pathogens or impair fungal antioxidation systems (Kim et al., 2012; Teixeira et al., 2013; Zhang et al., 2015; Shen et al., 2016; Ait Dra et al., 2017; Ji et al., 2018; Ma et al., 2019). In addition, such compounds were shown to augment the effect of antibacterial (Ait Dra et al., 2017; Kissels et al., 2017; Veras et al., 2017; Porter and Monu, 2019; Aksoy et al., 2020) and antifungal (Kordali et al., 2008; Kim et al., 2014, 2015, 2019; Rosato et al., 2018; Schlemmer et al., 2019) agents and to considerably enhance the pathogen sensitivity to antibiotics and antimycotics. In agriculture, this ability of natural redox-active products to improve the efficacy of chemical plant protection (Kim et al., 2017; Shcherbakova et al., 2019) and combat fungal strains resistant to industrial fungicides without increasing dosages (Campbell et al., 2012; Kim et al., 2012) could have significant importance, economically and ecologically.

The damaging and regulatory effects of redox-active molecules are realized through their interaction with lipids, proteins and DNA. These molecules cause lipid peroxidation, oxidative injury of the cell plasma membrane, protein, and DNA oxidation, as well as nitrosylation and S-glutathionylation of proteins (Belozerskaya and Gessler, 2007; Oktyabrsky and Smirnova, 2007). Thymol (2isopropyl-5-methylphenol), a monoterpene phenol, is the major component of essential oil of Thymus vulgaris found also in other Thymus and Lamiaceae species. Thymol attacks several cellular and metabolic targets in pathogenic fungi. It disrupts cell wall or membrane integrity and interferes with ergosterol biosynthesis (Ahmad et al., 2011; De Lira Mota et al., 2012). Thymol functions also as a redox-active compound, inducing generation of reactive oxygen species and lipid peroxidation in fungal cells (Gao et al., 2016; Shen et al., 2016). Earlier, we showed addition of thymol together with Dividend SC, 3\% (a.i. difenoconazole) into nutrient media significantly enhanced the inhibitory effect of this triazole fungicide on the colony growth of Bipolaris sorokiniana and Parastagonospora nodorum (Dzhavakhiya et al., 2012). Recently, we also demonstrated a potential for using thymol to overcome fungicide resistance of a $P$. nodorum strain that was able to grow on difenoconazole-containing media (Kartashov et al., 2019). However, the possibility to employ thymol as a chemosensitizing agent in seed or plant treatments to provide an effective suppression of the aforementioned plant pathogens by triazole fungicides, applied in lowered dosages, to date, not been tested. At the same time, lowering of effective dosages of these common fungicides could counter expanding pollution of agricultural areas with xenobiotics. In addition, the sensitized resistant strains could be rendered more vulnerable to the fungicides. In this regard, we explored whether seed or foliar treatments with two triazole-based formulations combined with thymol resulted in lowering effective fungicidal dosages in parallel with providing sufficient plant protection and effective control of the aforementioned pathogens. To this end, we studied the protective effect of difenoconazole (Dividend ${ }^{\circledR} 030$ FS) against B. sorokiniana, F. culmorum and also accompanying Fusarium and Alternaria species on seedlings grown from barley and wheat seeds treated with this fungicide in combination with thymol. In another experimental series, protection efficacy of wheat seedlings sprayed with thymol-combined tebuconazole (Folicur $^{\circledR} 250 \mathrm{EC}$ ) against $P$. nodorum was assessed. We found significant synergistic augmentation of the protective effect of both difenoconazole and tebuconazole when co-applied with thymol. In addition, a possibility to control a tebuconazoletolerant $P$. nodorum mutant strain by co-application of thymol with Folicur ${ }^{\circledR}$ was showed. We also analyzed deoxynivalenol $(\mathrm{DON})$ and zearalenone (ZEN) production in a toxigenic F. culmorum exposed to thymol and profiled expression of key genes associated with the biosynthesis of trichothecene or polyketide mycotoxins in this pathogen. These experiments demonstrated thymol at sensitizing concentrations did not stimulate DON and ZEN biosynthesis. Collectively, our findings 
confirm the promise of using chemosensitizing agents as an approach to controlling fungal pathogens in agriculture and possibly contributing to development of better environmentally friendly integrated crop protection systems.

\section{MATERIALS AND METHODS}

\section{Fungi}

Strains of Fusarium culmorum (OR-02-37) and Parastagonospora nodorum (B-9/47) pathogenic to wheat were provided by the State Collection of Plant Pathogenic Microorganisms at the All-Russian Research Institute of Phytopathology (ARRIP) and the ARRIP Department of Mycology, respectively. F. culmorum stock cultures of the fungi maintained on potato dextrose agar slants were resumed by culturing for 10-14 days in Petri plates on the same medium to obtain spore-producing colonies. Suspensions of fungal conidia for inoculations of wheat seeds with $F$. culmorum and detached wheat leaves with $P$. nodorum were prepared according to Shcherbakova et al. (2018) and Shagdarova et al. (2018), respectively.

Samples of barley grain naturally infected with Bipolaris sorokiniana, a common root rot agent, were collected from plants grown on the ARRIP experimental plots.

\section{Thymol and Fungicides}

Since thymol (CAS 89-83-8) is slightly soluble in water, solutions of $99 \%$ commercial thymol (>99\%; REARUS, Russia) in dimethyl sulfoxide, (CAS 67-68-5) 99.9\% (Panreac, Spain) were used for seed and leaf treatments. Commercial fungicides tested included Dividend ${ }^{\circledR} 030$ FS (a.i. difenoconazole, 3\%) and Folicur ${ }^{\circledR} 250$ EC (a.i. tebuconazole, 25\%), which are commonly applied for seed and foliar treatments of various crops, including cereals.

\section{Seed Treatments and Root Rot Development Assay}

To select non-phytotoxic dimethyl sulfoxide (DMSO) and thymol concentrations, spring wheat (cv. Zlata) and barley (cv. Zazersky 85) seeds (200 seeds per each treatment) were soaked overnight in aqueous $0.5,1.0$, or $10 \%$ DMSO or in thymol dissolved in the DMSO solutions to final concentrations 10, 100 , or $1000 \mathrm{ppm}$. After such treatments seeds were placed on paper towels (filter paper strips of $10 \mathrm{~cm} \times 50 \mathrm{~cm}$, 50 seeds per strip), which were rolled-up and put into beakers with distillated water. Plants were grown at $22^{\circ} \mathrm{C}$ (day) and $16^{\circ} \mathrm{C}$ (night), $60 \%$ relative humidity and 16-h light period for 7 days. Seeds treated with distillated water were used as controls. The number of germinated seeds, number of seedlings and their length were recorded after 7 days of plant growth.

Prior to conducting sensitization experiments, 50-g samples of non-disinfected barley seeds naturally infected by $B$. sorokiniana and wheat seeds artificially inoculated with F. culmorum were treated by a 3-h agitation in a minimal volume of aqueous Dividend $^{\circledR} 030$ FS allowing complete seed wetting. This was followed by $16-18 \mathrm{~h}$ incubation with the fungicide formulation at room temperature, without agitation. Prior to treatment with the fungicide, wheat seeds were disinfected (Shcherbakova et al., 2018), inoculated with F. culmorum using 1-h soaking in a conidial suspension $\left(10^{5}\right.$ conidia/ml $)$ at slow stirring, and then slightly dried. The highest difenoconazole concentration (500 ppm) used for fungicidal treatments of barley and wheat grain samples corresponded to Dividend ${ }^{\circledR} 030$ FS dose rate recommended for agricultural practice (State Catalogue of Pesticides and Agrochemicals, 2018) for pre-sowing treatments of wheat and barley seeds (2.5 L/1000 kg of grain). To select subfungicidal dosages, several lower concentrations of Dividend ${ }^{\circledR}$ ranging from 5.0 to $250 \mathrm{ppm}$ (i.e., from 0.15 to $7.5 \mathrm{ppm}$ based on difenoconazole) were tested. After these treatments, the Dividend-exposed and water-exposed (control) seeds were assayed using rolled-towel test, as described above. After 1214 days post-inoculation, the number of diseased seedling were counted to evaluate root rot incidence, and disease symptoms on were roots and root necks were visually estimated according to a five-score rating scale (Shcherbakova et al., 2018) to determine the average disease index.

Following the determination of sub-fungicidal Dividend ${ }^{\circledR}$ dosages and non-phytotoxic concentrations of DMSO-dissolved thymol, the respective fungicide and sensitizer dosages were used for combined treatments of barley seeds, naturally infected with B. sorokiniana, and wheat seeds, artificially inoculated with $F$. culmorum, as described above. Incidence and disease severity (R\%) of common root rot and Fusarium root rot, on barley and wheat seedlings, respectively, were assayed using the rolled-towel test in parallel with the treatments with the fungicide alone. The incidence of Fusarium spp. and Alternaria spp. accompanying the predominant $B$. sorokiniana infection of barley seeds was also evaluated.

\section{Evaluation of Folicur ${ }^{\circledR}$ Effect Against Parastagonospora nodorum Detached Leaf Assay}

In order to determine thymol concentrations, which did not injure wheat leaves but produced a minor disease-suppression effect (Table 1), detached wheat leaves were treated as described previously (Shagdarova et al., 2018). Briefly, P. nodorum spores were suspended to a final concentration of $10^{6}$ conidia/ml in $1 \%$ aqueous DMSO or thymol (from 10 to $5000 \mathrm{ppm}$ ) dissolved in $1 \%$ DMSO. Control conidial suspensions $\left(10^{6}\right.$ per $\left.\mathrm{ml}\right)$ were prepared in sterile distilled water (SDW). Eight centimeter long leaf fragments were cut from central parts of detached wheat leaves and placed in Petri plates atop of 1\% water agar supplemented with benzimidazole $(40 \mu \mathrm{g} / \mathrm{ml})$. Aliquots $(10 \mu \mathrm{l})$ of the conidial suspensions in DMSO or thymol solutions were dropped on upper (distal) parts of $8-\mathrm{cm}$ leaf fragments. Drops $(10-\mu \mathrm{l})$ of conidial suspensions $\left(10^{6}\right.$ conidia/ml) in SDW (control for DMSO-treated detached leaves) or 1\% DMSO solutions (control for thymol-treated leaves) were applied to lower (basal) parts of the same $8-\mathrm{cm}$ leaf fragments. In situ disease development was recorded on 10 leaf sections per each treatment. An additional plate, in which both distal and basal locations on each of 10 leaf fragment were inoculated with pathogenic conidia in SDW, was prepared to confirm that they was able to cause the 
TABLE 1 | Effect of treatments of detached wheat leaves with Folicur ${ }^{\circledR} 250$ EC or thymol solutions in DMSO on the severity of blotch symptoms caused by Parastagonospora nodorum.

\begin{tabular}{lcc}
\hline Leaf treatments & Average score* $^{*}$ & Disease suppression, \% of control \\
\hline $\mathrm{H}_{2} \mathrm{O}$ & $2.97^{\mathrm{a}}$ & - \\
$1 \% \mathrm{DMSO}$ & $2.95^{\mathrm{a}}$ & 0.6 \\
Thymol in 1\% DMSO, ppm & & \\
5000 & $0.55^{\mathrm{b}}$ & 81.3 \\
500 & $1.90^{\mathrm{c}}$ & 35.6 \\
100 & $2.60^{\mathrm{d}}$ & 10.5 \\
50 & $2.80^{\mathrm{a}}$ & 5.2 \\
10 & $2.98^{\mathrm{a}}$ & 0.0 \\
Folicur & \\
0.5 & & 86.5 \\
0.25 & $0.40^{\mathrm{b}}$ & 45.0 \\
0.1 & $1.63^{\mathrm{e}}$ & 28.3 \\
0.05 & $2.13^{\mathrm{f}}$ & 4.0 \\
\hline
\end{tabular}

*The mean of three replicated assays, 10 detached leaf fragments per treatment in each assay. Mean values indicated with different superscript letters are significant ( $p \leq 0.05$ : $t$-test for independent variables, STATISTICA 6.0). ${ }^{* *}$ Percent suppression calculated relative to scores in corresponding control treatments of leaf fragments: water or 1\% DMSO for fungicide or thymol, respectively (see section "Materials and Methods," "Detached Leaf Assay"). A five score rating scale (1 - small dark lesions; 2 - dark-brown clearly bordered spots, leaf tissue remains green; 3 - light-brown or brown growing spots edged with chlorosis; 4 - light-brown or brown, pycnid formation) was used (Shagdarova et al., 2018).

disease. Disease symptoms were scored at 5 days post-inoculation according to a five-score rating. Sub-fungicidal dosages of Folicur $^{\circledR} 250 \mathrm{EC}$, tested at concentrations ranging from 0.05 to $0.5 \mathrm{ppm}$ (based on tebuconazole) were determined using the same assay (Table 1). This assay was also used to assess efficacy of Folicur $^{\circledR}$ combined with thymol against a tebuconazole-resistant P. nodorum mutant.

\section{Foliar Treatment of Wheat Seedlings Under Controlled Conditions}

Spring wheat seedlings (cv. Khakasskaya) were grown in pots (25-30 seedlings per pot, four pots per treatment) to the twothree leaf stage under controlled conditions (at $21^{\circ} \mathrm{C}$ during $16-\mathrm{h}$ photoperiod and $18^{\circ} \mathrm{C}$ during dark, respectively, and $60 \%$ relative humidity). Young seedlings were sprayed with $P$. nodorum spore suspensions $\left(10^{6}\right.$ conidia/ml, $30 \mathrm{ml}$ per each treatment) supplemented with Folicur ${ }^{\circledR}$ alone or DMSO-dissolved thymol alone, each taken at two sub-fungicidal $(0.1$ and $0.25 \mathrm{ppm}$ of tebuconazole) or two marginally fungitoxic (50 and $100 \mathrm{ppm}$ of thymol) dosages. In parallel, another seedling series was sprayed with fungal conidia suspended in solutions of the fungicide at a concentration of $0.1 \mathrm{ppm}$ combined with thymol at 50 or $100 \mathrm{ppm}$. To promote infection, pots with treated and inoculated seedlings were maintained in an inocubation chamber at $80-85 \%$ relative humidity and $18^{\circ} \mathrm{C}$ for $24 \mathrm{~h}$. Thereafter plant growing was continued under above-mentioned controlled conditions for 2 weeks. The disease development was scored according to the commonly approved international James'scale (James, 1971) at 14-15 days post-inoculation (the tillering stage Z25, Zadoks et al., 1974) as recommended for registration of early disease symptoms on spring wheat in Non-Chernozem zone of Russia (Sanin and Sanina, 2013).

\section{Mycotoxin Production Assessment}

To estimate production of deoxynivalenol (DON) and zearalenone (ZEN), a toxigenic F. culmorum strains, Fc-M-01$55 / 3$, was grown in submerged culture for 7-9 days at $25^{\circ} \tilde{\mathrm{N}}$ and 220 rpm (New Brunswick ${ }^{\mathrm{TM}}$ Excella E25/25R incubation shaker, New Brunswick Scientific, United States) in 250-ml shaker flasks with toxigenesis-promoting liquid Myro medium (Greenhalgh et al., 1988) supplemented with thymol to a final concentration of $50 \mathrm{ppm}$. Fungal biomass obtained by the submerged culturing was used to assess expression of toxigenesis-associated genes. To prepare other series of samples of fungal mycelia for expression analyses, Fc-M-01-55/3 colonies were also grown in the presence of the same thymol concentration on the same medium with $1.5 \%$ agar in $90-\mathrm{mm}$ Petri plates at $25^{\circ} \mathrm{C}$ for $5-7$ days. Thymol was dissolved in $1.0 \%$ aqueous DMSO sterilized by filtration through $0.22 \mu \mathrm{m}$ Millipore membrane filters (MilliporeSigma, United States) and added in the liquid medium or the melted agar medium prior to inoculation. The media were inoculated by addition of a pathogen spore suspension $\left(10^{6}\right.$ conidia/ml $)$ or by placing a piece of fungal mycelium grown on PDA into the center of the plates. Fungal cultures grown in/on thymol-free media supplemented with corresponding aliquots of $1.0 \%$ DMSO under the same conditions served as controls.

\section{Mycotoxin Quantification in Submerged F. culmorum Cultures}

Upon completion of the cultivation, DON and ZEN were quantified by reverse phase HPLC using a Waters 1525 Breeze HPLC system equipped with a Waters 2487 UV detector, applying isolation procedures slightly modified from those described previously (Shcherbakova et al., 2018; Stakheev et al., 2018). Briefly, the submerged culture of each experimental or control flask was extracted twice with an equal volume of ethyl acetate or dichloromethane (to isolate $\mathrm{ZEN}$ or $\mathrm{DON}$, respectively) for 1 -h on an incubator shaker at $220 \mathrm{rpm}$ and $25^{\circ} \mathrm{C}$. Mycelia were separated by centrifugation and dried at $102^{\circ} \mathrm{C}$ up to a constant weight. Organic phases of supernatants were passed through a layer of anhydrous $\mathrm{Na}_{2} \mathrm{SO}_{4}$ and evaporated on a rotary evaporator at $40^{\circ} \mathrm{C}$. Dry residues were dissolved in a mixture of acetonitrile, methanol and water (1:1:0.75) or (1:1:4.0) used as mobile phases in RP-HPLC analyses of ZEN or DON, respectively. Aliquots $(10 \mu \mathrm{L})$ of the prepared solutions were applied on a temperature-controlled Symmetry C18 (5 $\mu \mathrm{m}, 4.6 \mathrm{~mm} \times 150 \mathrm{~mm})$ column followed by toxin elution, using the above-mentioned mobile phases, and detected at $254 \mathrm{~nm}$. Mycotoxin concentrations $(\mu \mathrm{g} / \mathrm{mg}$ ) were calculated using a calibration curve based on commercial DON and ZEN preparations (Sigma-Aldrich Corp., United States), which were also added in extracts obtained from control fungal cultures as external standards. All samples were analyzed twice. The limits of detection were $0.5(\mathrm{DON})$ and $0.2(\mathrm{ZEN}) \mathrm{ng} / \mathrm{mg}$; the recovery levels averaged $81 \%$ and $77 \%$ for DON and ZEN, respectively. 


\section{RNA Extraction and Reverse Transcription}

Total RNA was extracted from fungal mycelium using RNeasy ${ }^{\circledR}$ Plant Mini Kit (QIAGEN, Germany) according to manufacturer's protocol. Ten microgram of total RNA were used for cDNA synthesis carried out by the MMLV RT kit (Evrogen JSC, Russia).

\section{Quantitative PCR}

Expression levels of the following four genes responsible for different steps of trichothecene and polyketide biosynthesis were quantified by qPCR: TRI5 (trichodiene synthase), TRI6 (transcription factor), PKS4 and PKS13 (polyketide synthesis) were analyzed by qPCR. The translation elongation factor 1 alpha gene $(T E F 1 \alpha)$ served as a control as the most suitable housekeeping gene according to Kim and Yun (2011). The sequences of primers and probes are presented in Table 2. The ClustalX algorithm and Oligo 6.71 program were used for designing gene-specific primers and estimation of their physical properties, respectively. qPCR analyses were performed in a DT96 thermal cycler (DNA-technology, Russia) according to the following conditions: $94^{\circ} \mathrm{C}$ for $1 \mathrm{~min}$ followed by 45 cycles at $94^{\circ} \mathrm{C}$ for $10 \mathrm{~s}, 64^{\circ} \mathrm{C}$ for $15 \mathrm{~s}, 72^{\circ} \mathrm{C}$ for $10 \mathrm{~s}$, and finally $72^{\circ} \mathrm{C}$ for $3 \mathrm{~min}$. The PCR mix composition was described earlier (Stakheev et al., 2016). Threshold method was used for quantification cycle calculation and analysis of results. qPCR amplification efficiency was calculated using the $\mathrm{C}_{q}$ slope method. QGene96 software was used for analyzing the qPCR results.

\section{Data Analysis and Statistics}

Data obtained in the experiments involving seed treatments and spraying of wheat seedlings were analyzed using a STATISTICA 6.1 software (StatSoft Inc.). Mean values, standard deviations and standard errors were calculated. Significant difference between treatments and controls were determined using a $t$-test for independent variables at $p \leq 0.05$. Experiments involving spraying of wheat seedlings (100-120 ones for each treatment) or assessment of Alternaria incidence on barley seeds were replicated four times. Other experiments were run in triplicate. Each independent experiment with barley or wheat gain included 200 seeds per treatment.

Protection efficacy (PE) was calculated using formula $\mathrm{PE} \%=\mathrm{Dc}-\mathrm{Dt} / \mathrm{Dc} \times 100$, where $\mathrm{Dc}$ is the average incidence or disease severity in controls, while Dt represents these parameters for treated seeds or seedlings.

To reveal a putative synergy between thymol and tebuconazole or difenoconazole in co-applications on seeds or seedlings, the Limpel criterion, Er $\geq$ Ee (at $p \leq 0.05$ ), was determined (Richer, 1987). In this inequality, Er represented PE\% obtained when Dividend $^{\circledR}$ or Folicur ${ }^{\circledR}$ was combined with thymol. Ee is an expected additive effect, i.e., the estimated $\mathrm{PE} \%$ that could result from summing the protective efficacy of each of components alone calculated using the formula $\mathrm{Ee}=(\mathrm{X} \%+\mathrm{Y} \%)-$ $\mathrm{X} \% \times \mathrm{Y} \% / 100$, where $\mathrm{X} \%$ and $\mathrm{Y} \%$ are $\mathrm{PE} \%$ of thymol or the fungicide.

\section{RESULTS}

\section{Improved Protective Efficacy of Triazoles Combed With Thymol}

\section{Enhancing the Fungicidal Effect of Dividend ${ }^{\circledR}$ Against Root Rot Agents}

The testing phytotoxic effects of DMSO and thymol, which preceded the experiments on individual and thymol-combined fungicidal treatments, showed there was no inhibition of wheat seed germination and seedling formation after seed soaking in $0.5 \%$ or $1.0 \%$ DMSO. Application of $10 \%$ DMSO on barley seeds strongly suppressed germination (Table 3). The highest concentration of thymol (1000 ppm) in 10\% DMSO was phytotoxic for wheat and barley based on roll-towel assay. However, thymol at a concentration of $100 \mathrm{ppm}$ dissolved in $1 \%$ DMSO was not phytotoxic to seeds of wheat, but was toxic to barley seeds, but did not impede the development of barley seedlings when applied at lower concentrations (Table 3). Based on the results of these initial phytotoxicity assays, thymol at a final concentration of $50 \mathrm{ppm}$ dissolved in 1\% DMSO was selected for further chemosensitization experiments on barley and wheat seeds, naturally or artificially infected with fungal root rot agents, respectively.

The highest concentration of difenoconazole in our experiments reflected the commercial fungicidal dosage recommended for grain treatments with Dividend ${ }^{\circledR}$ to protect wheat and barley plants against Fusarium and common

TABLE 2 | Gene-specific primers and hydrolysis probes used.

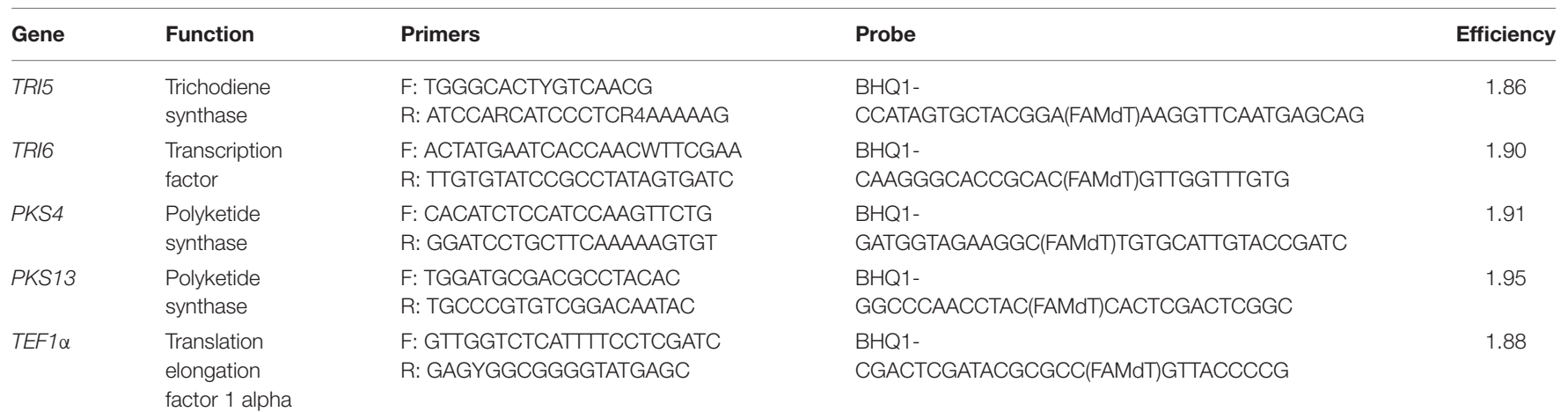


TABLE 3 | Influence of wheat and barley seed treatments with dimethyl sulfoxide (DMSO) and thymol dissolved in DMSO on seedling formation.

\begin{tabular}{|c|c|c|}
\hline Plant & Treatments & Seedlings number, $\%$ *** \\
\hline \multirow[t]{8}{*}{ Wheat $^{\star}$} & Control, water & $96^{\mathrm{a}}$ \\
\hline & $10 \%$ DMSO & $54^{b}$ \\
\hline & Thymol (1000 ppm) in 10\% DMSO & $36^{c}$ \\
\hline & $1 \%$ DMSO & $94^{\mathrm{a}}$ \\
\hline & Thymol (100 ppm) in 1.0\% DMSO & $92^{\mathrm{a}}$ \\
\hline & Thymol (50 ppm) in 1.0\% DMSO & $89^{a}$ \\
\hline & $0.5 \%$ DMSO & $95^{\mathrm{a}}$ \\
\hline & Thymol (10 ppm) in 0.5\% DMSO & $90^{a}$ \\
\hline \multirow[t]{7}{*}{ Barley $^{\star \star}$} & Control, water & $57^{b}$ \\
\hline & $10 \%$ DMSO & $9^{d}$ \\
\hline & Thymol (1000 ppm) in 10\% DMSO & 0 \\
\hline & $1 \%$ DMSO & $55^{\mathrm{c}}$ \\
\hline & Thymol (100 ppm) in 1.0\% DMSO & $39^{c}$ \\
\hline & Thymol (50 ppm) in 1.0\% DMSO & $55^{\mathrm{b}}$ \\
\hline & Thymol (10 ppm) in 0.5\% DMSO & $61^{b}$ \\
\hline
\end{tabular}

*Seeds were surface-disinfect before treatments as described earlier (Shcherbakova et al., 2018). ${ }^{* * N o n-d i s i n f e c t ~ s e e d s ~ n a t u r a l l y ~ i n f e c t e d ~ b y ~}$ fungal root rot agents. ${ }^{* *}$ Percent relative to total seed number. Difference between means (200 seeds per treatment in each of three experiments) indicated with the same letters are insignificant at $p \leq 0.05$ (t-test for independent variables, STATISTICA 6.0).

root rots. For three other treatments, this fungicide was used at dosages half, 10 and a 100 times lower than the highest concentration (i.e., at 7.5, 1.5, and $0.15 \mathrm{ppm}$ based on difenoconazole). These four dosages are indicated below as Dividend/1 (the highest), Dividend/05, Dividend/01, and Dividend/001, respectively. Results of roll-towel assays showed Dividend/1 and Dividend/05 were effective against common root rot infection on barley seedling, while Dividend/01 was the lowest dosage still inhibiting development of B. sorokiniana, a predominant seed pathogen, and did not affect seed germination (Table 4). As with naturally infected barley grain, Dividend/01 was the lowest sub-fungicidal dosage when using artificial inoculations of wheat seeds with F. culmorum (Table 5). Based on these results, Dividend/01, i.e., the dosage tenfold lower than recommended in agricultural practice, was selected for subsequent chemosensitization experiments.

Studying the thymol ability to potentiate fungicidal effect of Dividend ${ }^{\circledR}$ toward B. sorokiniana showed this redox-active compound was able to sensitize the pathogen to difenoconazole in combined treatments of naturally infected barley seeds. Significantly higher disease suppression was found on seedlings grown from seeds treated with the fungicide combined with thymol, compared to seedlings germinated from seeds treated with Dividend/01 alone (Figure 1). After co-application on seeds, an almost fivefold decrease in pathogen incidence was observed on barley seedlings, and disease severity (R\%) was six times lower than that on seedlings grown from seeds, which were soaked in Dividend/01 alone. Moreover, in our experiments, combining the fungicide with thymol provided an almost equal antifungal effect as the tenfold higher dosage, Dividend/1, recommended for agricultural practice. The real antifungal effect of the combined
TABLE 4 | Development of $B$. sorokiniana on barley seedlings grown from naturally infected seeds treated with Dividend ${ }^{\circledR} 030$ FS.

\begin{tabular}{lccc}
\hline Treatments & $\begin{array}{c}\text { Seed } \\
\text { germination, } \%\end{array}$ & Common root rot (B. sorokiniana)* \\
\cline { 3 - 4 } & & Diseased & Average \\
& & seedlings, $\%$ & disease index \\
\hline Control (no fungicide) & $87.0^{\mathrm{a}}$ & $49.4^{\mathrm{a}}$ & $2.8^{\mathrm{a}}$ \\
Dividend/1 & $75.0^{\mathrm{b}}$ & $8.7^{\mathrm{b}}$ & $0.3^{\mathrm{b}}$ \\
Dividend/05 & $65.0^{\mathrm{b}}$ & $20.0^{\mathrm{c}}$ & $0.8^{\mathrm{c}}$ \\
Dividend/01 & $87.0^{\mathrm{a}}$ & $30.5^{\mathrm{d}}$ & $2.0^{\mathrm{d}}$ \\
Dividend/001 & $85.0^{\mathrm{a}}$ & $49.4^{\mathrm{a}}$ & $2.8^{\mathrm{a}}$ \\
\hline
\end{tabular}

*The means of three experiments ( $n=200$ per treatment in each). Dividend ${ }^{\circledR} 030$ FS dosage recommended for grain treatments against Fusarium and common root is indicated as Dividend/1; Dividend/05, 101, and /001 represent twofold-, tenfold-, and hundredfold-diminished dosages, respectively. Means within each column indicated with different superscript letters are significantly different ( $p \leq 0.05$; $t$ test for independent variables, STATISTICA 6.0). A five-score rating scale $(0-$ no disease symptoms; 1- weak symptoms: brown streaks or spots on roots and above; 2 - medium-manifested symptoms; 3 - strong extensive symptoms, 4 crown and root decaying or plant death) was used (Shcherbakova et al., 2018).

TABLE 5 | Development of Fusarium culmorum on wheat seedlings grown from artificially infected seeds treated with different dosages of Dividend ${ }^{\circledR} 030$ FS.

\begin{tabular}{|c|c|c|c|}
\hline \multirow[t]{2}{*}{ Treatments } & \multirow{2}{*}{$\begin{array}{c}\text { Seed } \\
\text { germination, \% }\end{array}$} & \multicolumn{2}{|c|}{ Fusarium root rot (F. culmorum) } \\
\hline & & $\begin{array}{c}\text { Diseased } \\
\text { seedlings, \% }\end{array}$ & $\begin{array}{c}\text { Average } \\
\text { disease index }\end{array}$ \\
\hline Control (no fungicide) & 95.0 & $84.3^{\mathrm{a}}$ & $3.6^{a}$ \\
\hline Dividend/1 & 95.0 & $54.5^{b}$ & $1.9^{b}$ \\
\hline Dividend/05 & 94.0 & $80.3^{\mathrm{a}}$ & $2.3^{\mathrm{b}}$ \\
\hline Dividend/01 & 95.0 & $71.4^{\mathrm{c}}$ & $3.1^{\mathrm{a}}$ \\
\hline Dividend/001 & 96.0 & $79.2^{\mathrm{a}}$ & $3.5^{\mathrm{a}}$ \\
\hline
\end{tabular}

*Numbers in the columns represent the means of three experiments $(n=200$ per treatment in each). Means indicated with different letters are significant at $p \leq 0.05$. For additional explanations, see captions to Tables 3, 4.

treatments (Er) significantly exceeded not only the impact of Dividend/01, taken alone, but also the calculated additive effect (Ee) expected if there was no synergy (Figure 1). Hence, the elevated protective efficacy of the co-applications resulted from a synergy (Richer, 1987) between thymol and difenoconazole.

In addition to the predominant root rot pathogen, B. sorokiniana, we found in preliminary mycological analyses that the barley seeds used were naturally infected with Fusarium spp. and Alternaria spp. as minor infections with the incidence $10.5 \%$ and $7 \%$ in DMSO-treated control, respectively. Therefore, we examined the effect of the fungicide-and-thymol treatments against these causative agents, as well. Twofold reduction of Alternaria incidence was noticed on the seedlings if Dividend/01 was applied on the seeds conjointly with thymol in two of four performed assays (to 2.7 and $3.5 \%$ ), but no effect was found in two other ones. Compared to controls, the average incidence of Fusarium rot agents on seedlings decreased to $6.4 \%$ or $3.2 \%$ after seed treatments with Dividend/01, alone, or Dividend/01 + thymol at $50 \mathrm{ppm}$, respectively. 


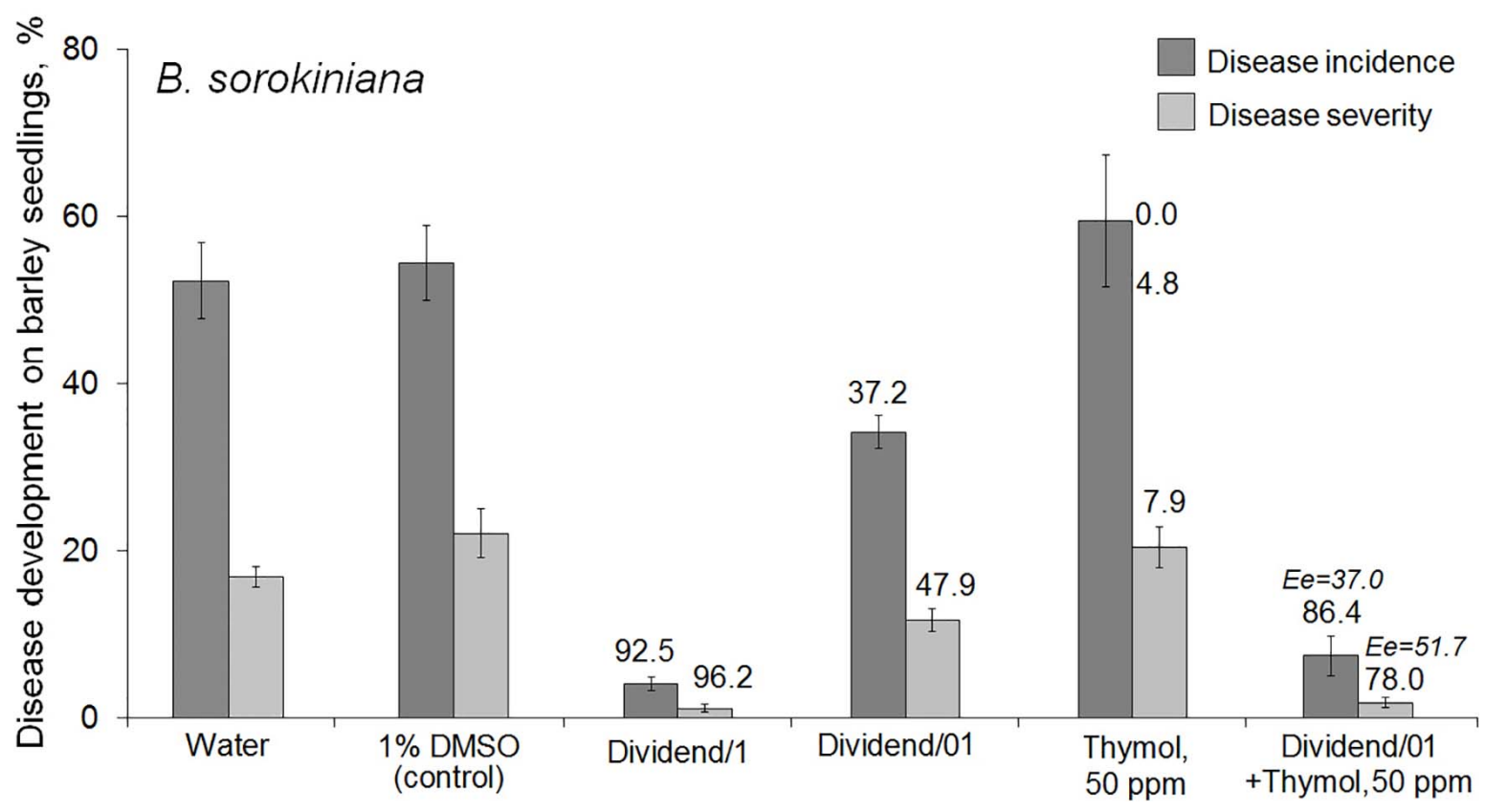

FIGURE 1 | Effect of seed treatments with Dividend ${ }^{\circledR}$ alone, thymol alone or their combination on the development of a root rot agent, Bipolaris sorokiniana, on spring barley seedlings (cv. Zazersky 85). Dividend/1, the fungicide dosage recommended for industrial seed treatments. Dividend/01, the fungicide dosage ten times lower than recommended. In treatments involving thymol, it was used as a solution in 1\% dimethyl sulfoxide (DMSO). Numbers in regular font above the columns show percent disease suppression observed in experiments (Er). Percent suppression calculated for expected additive effect (Ee) is indicated with italic numbers (see section "Materials and Methods," "Data Analysis and Statistics"). Disease incidence was determined as the average percent of rotted seedlings compared to DMSO-treated controls. Disease severity was calculated by formula: $R \%=\Sigma(n \times d) / 4 N \times 100$, where $n-$ the number of seedlings with the same disease index; $d$ - the disease index according to a score rating scale (from 0 to 4); $\mathrm{N}$ - the number of seedlings per treatment; 4 - the maximal score in the scale (Shcherbakova et al., 2018). Results are expressed as the means of three independent roll-towel assays, 200 seeds per treatment in each assay. Y-bars show SE with a 95\% confidence interval ( $p \leq 0.05, t$-test for independent variables; STATISTICA v. 6.1, StatSoft Inc.).

Co-application of thymol and Dividend ${ }^{\circledR}$ on artificially inoculated wheat seeds also resulted in augmentation of the suppressive activity of this triazole fungicide against $F$. culmorum (Figure 2). After co-applications of Dividend/01 combined with thymol, both incidence and severity of the disease on wheat seedlings were almost twice as low compared to application of Dividend/01 only. Comparisons of Er with Ee values suggested the augmented fungicidal effect obtained in experiments involving artificial seed inoculation was most likely a result of both sensitizing and fungitoxic activity of thymol. Thus, reduction of $F$. culmorum incidence on wheat seedlings after the fungicide-thymol co-application significantly exceeded the estimated additive effect. However, mitigation of disease severity by these combined applications was induced to a certain degree by an additive interaction of the fungicide and thymol rather than by chemosensitization (Figure 2). Nevertheless, joint influence of Dividend/01 and thymol on the Fusarium root rot agent had total fungicidal effect equal to the effect of a tenfold higher dosage of the fungicide, alone.

\section{Enhancing the Fungicidal Effect of Folicur ${ }^{\circledR}$ Against Parastagonospora nodorum}

Thymol was found to augment protective action of Folicur ${ }^{\circledR}$ EC 250 against $P$. nodorum in foliar treatments of wheat seedlings grown under controlled conditions. Spraying of wheat seedlings with thymol at $50 \mathrm{ppm}$ or with the fungicide at $0.1 \mathrm{ppm}$ did not sufficiently suppress disease development. In contrast, the combined treatment with the same doses of tebuconazole and thymol increased the antifungal effect. The coapplications resulted in disease suppression at a level exceeding the effect of the higher dosage of the fungicide $(0.25 \mathrm{ppm})$ after application of fungicide, alone (Figure 3). Calculation of Limpel's criterion (Richer, 1987) pointed to existence of synergy between thymol and tebuconazole in both combinations used. Er values (58.8 and 67.2\%) exceeded Ee values (35.7 and $43.0 \%$ ) at $p=0.02$ and 0.03 , respectively (Figure 3 ). Thus, joint treatments of wheat seedlings with fungicide and sensitizer produced an enhanced protective effect without increasing fungicide dosage.

Thymol-Folicur $^{\circledR}$ combinations were used against a $P$. nodorum mutant strain manifesting tolerance to this fungicide. This mutant was able to grow on PDA supplemented with tebuconazole concentrations up to $1.25 \mathrm{ppm}$ (i.e., up to $5 \mathrm{ppm}$ based on the formulation) that was lethal to a sensitive wild strain (Figure 4A). Both thymol and tebuconazole at dosages of $50 \mathrm{ppm}$ and $0.05 \mathrm{ppm}$, respectively, did not show a protective effect against the tolerant pathogen when applied separately. In contrast, the combined treatment at these dosages 


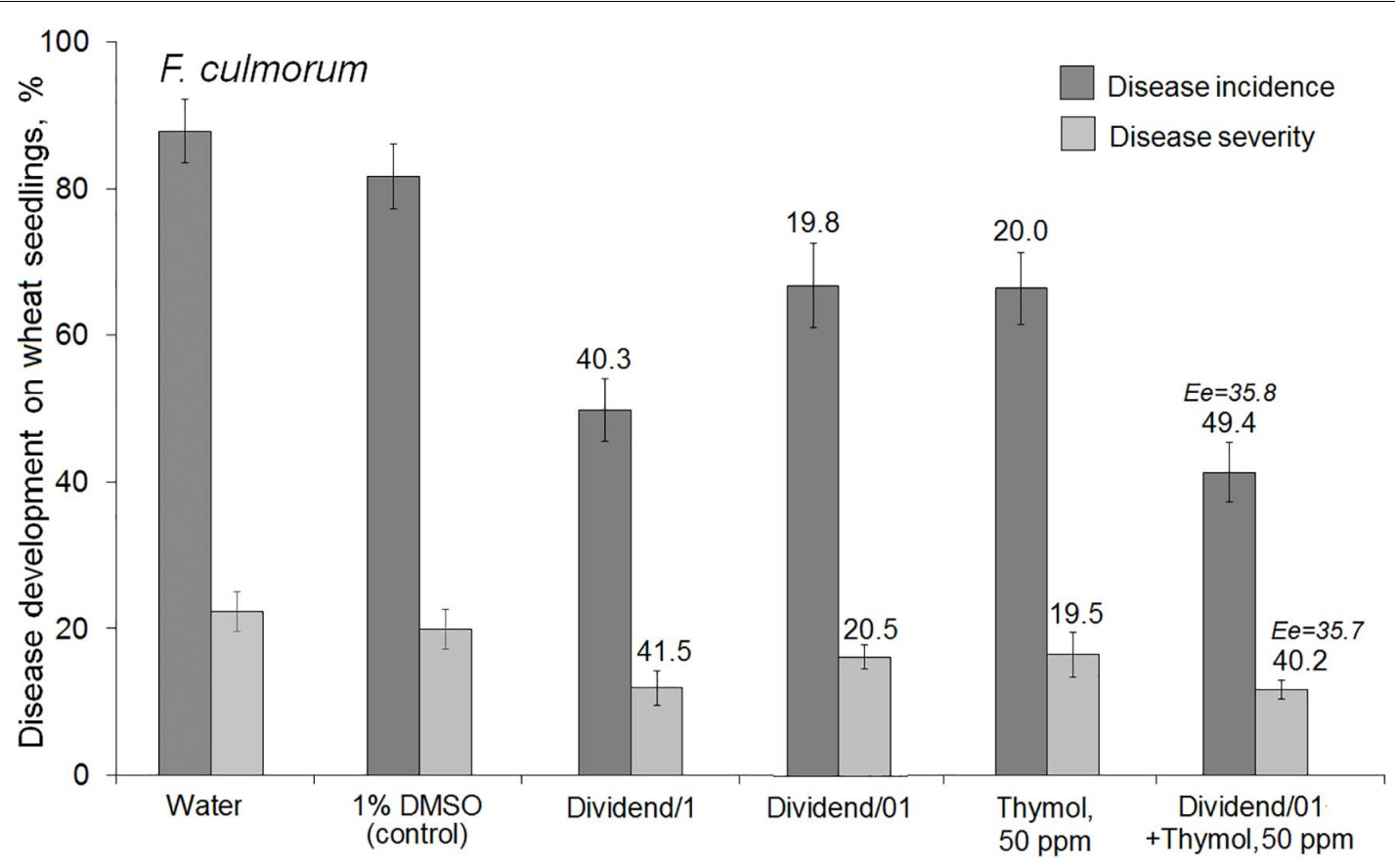

FIGURE 2 | Influence of seed treatments with Dividend ${ }^{\circledR}$ alone, thymol alone or their combination on the development of Fusarium root on spring wheat seedlings (cv. Zlata) from seeds artificially inoculated with F. culmorum. Dividend/1 and Dividend/01, the fungicide dosage recommended for industrial seed treatments and tenfold-lower dosage, respectively. Numbers above columns show Er values, while an expected additive effect (Ee) is indicated with italic numbers. The means of three independent roll-towel assays ( $n=200$ seeds per treatment in each assay). Y-bars show SE $(p \leq 0.05)$. For additional explanations, see caption to Figure 1 and section "Materials and Methods," "Data Analysis and Statistics."

resulted in an observable mitigation of lesions on detached leaves inoculated with either the wild or with the tolerant strain (Figure 4B).

\section{Mycotoxin Production by Toxigenic Fusarium culmorum Exposed to Thymol}

To ensure thymol did not induce production of sesquiterpenoid or polyketide fusariotoxins, DON and ZEN content was analyzed by HPLC after culturing a toxin-producing F. culmorum strain in media supplemented with thymol at $50 \mathrm{ppm}$, the concentration used to sensitize the pathogen to Dividend ${ }^{\circledR}$. In addition, expression levels of selected genes associated with mycotoxin production by Fusarium fungi (Lysøe et al., 2006; Kimura et al., 2007; Villafana et al., 2019) were explored.

No statistically significant increase of DON and ZEN concentrations compared to control was determined using HPLC (Table 6). Expression levels of key mycotoxin biosynthetic genes of F. culmorum were analyzed by qPCR for four genes, two (TRI5 and TRI6) localized in the trichothecene biosynthetic cluster and two (PKS4 and PKS13) belonging to the polyketide biosynthetic cluster. Gene expression was analyzed 2 days before the maximal accumulation of DON or ZEN in thymol-containing culture media inoculated with the pathogen. Levels of TRI5, TRI6, $P K S 4$, and PKS13 expression were compared to those in control fungal cultures grown without thymol under the same conditions. Expression of the control gene $(T E F 1 \alpha)$ was stable in all the samples tested. Expression levels of four target genes in thymolexposed samples were the same or slightly lower those of the control, in both submerged and agar cultures (Figure 5).

\section{DISCUSSION}

Thymol appears to be a promising chemosensitizing agent for various pathogenic and opportunistic fungi, based on several in vitro studies. For instance, Kim et al. (2015) found thymol synergistically interacted with another redoxactive molecule, 2-hydroxy-4-methoxybenzaldehyde (2H4M), augmenting the efficacy of cell wall disruption by these compounds and enhancing their effect against Aspergillus fumigatus and Aspergillus parasiticus. Thymol and 2H4M co-applications resulted also in a lowering of fungicidal concentrations and an elevated antifungal activity of these compounds for Aspergillus flavus, Saccharomyces cerevisiae, and Penicillium strains, despite fractional inhibitory concentration indices (FICIs) pointing to the absence of a calculated synergism (Kim et al., 2015). Accordingly, Guarda et al. (2011) demonstrated the synergistic effect between thymol and its isomer, caracole, toward Aspergillus niger growth inhibition. A partial synergism was revealed when thymol was tested in combinations with monoterpene- and phenol-containing citronella and garlic essential oils used to inhibit Penicillium corylophilum causing a spoilage of dried meat foods (Ji et al., 2019). Thymol displayed also in vitro synergistic interaction with 


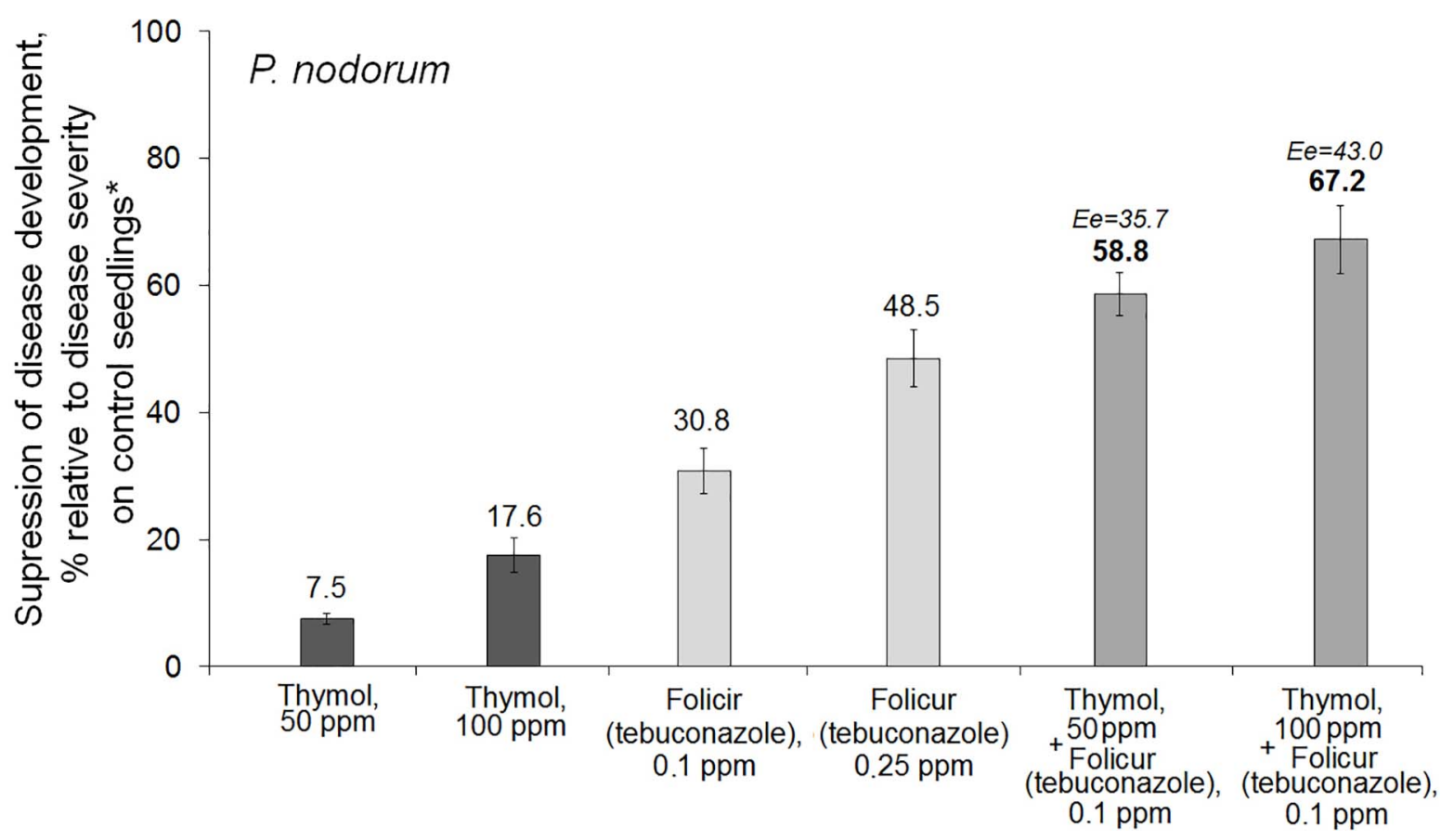

FIGURE 3 | Histograms showing the inhibitory effect of Folicur ${ }^{\circledR}$ EC 250 on development of Parastagonospora nodorum, a glume/leaf blotch agent, on wheat seedlings treated with thymol alone and the fungicide either alone or in two combinations with thymol. *The average percentage of disease development (100-120 seedlings per treatment); control plants were sprayed with $P$. nodorum conidia in water. The means of four experiments; Y-bars indicate SE (see section "Materials and Methods," "Data Analysis and Statistics" and caption to Figure $\mathbf{1}$ for additional explanations).

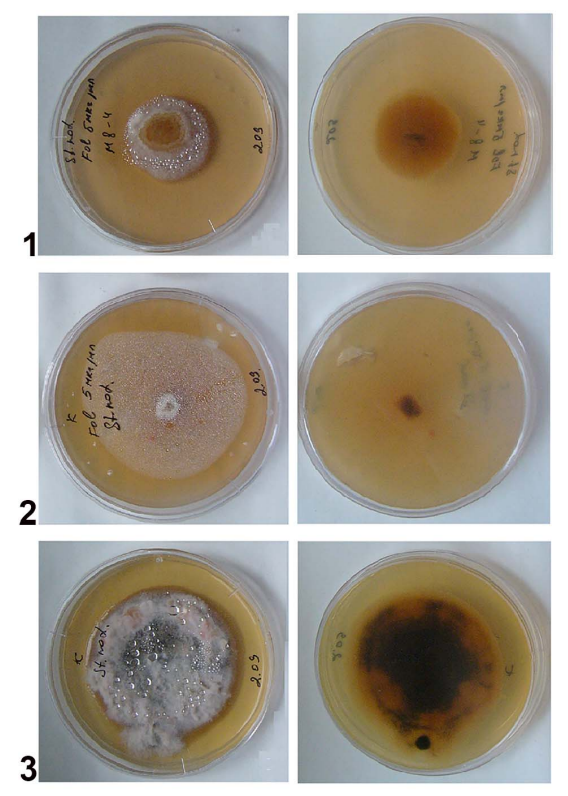

A
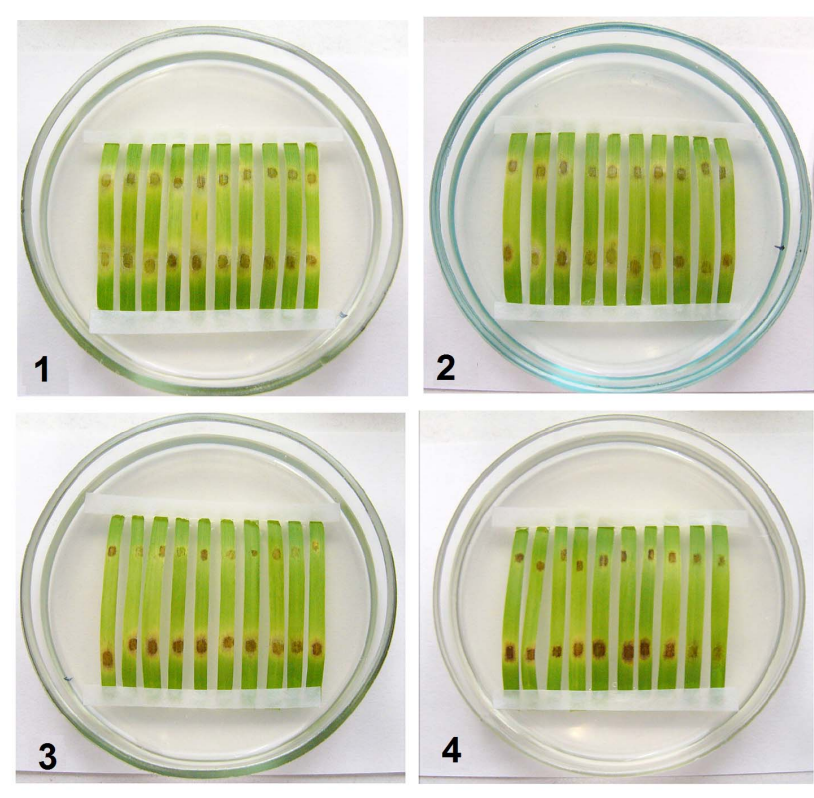

B

FIGURE 4 | (A) Colonies of tebuconazole-tolerant mutant (1) and wild $\mathbf{( 2 , 3 )}$ strains of Parastagonospora nodorum, grown on potato-dextrose agar containing Folicur $^{\circledR}$ (1 and $\mathbf{2}$ ) or not containing Folicur ${ }^{\circledR}$ (3) Photos in the right column show fungal colonies on reverse side of the plates. (B) $P$. nodorum blotch lesions on leaf fragments cut from detached wheat leaves. $(\mathbf{1}, \mathbf{2}, \mathbf{4})$, tebuconazole-tolerant mutant; (3), wild strain. Upper (distal) portions of leaf fragments are inoculated with a suspension of conidia $\left(10^{6} / \mathrm{ml}\right)$ supplemented with Folicur ${ }^{\oplus}$ alone (1), thymol alone (2) or their mixture (3 and $\left.\mathbf{4}\right)$ containing the same dosages as used for $\mathbf{( 1 , 2 ) . ~}$ Lower (basal) portions of leaf fragments are inoculated with conidia suspended in water to the same final concentration of $10^{6}$ per $\mathrm{ml}$. 
TABLE 6 | Deoxynivalenol (DON) and zearalenone (ZEN) production by a toxigenic F. culmorum strain cultured in thymol-containing Myro medium.

\begin{tabular}{lcccc}
\hline Thymol, ppm & \multicolumn{4}{c}{ Mycotoxins, $\boldsymbol{\mu} \mathbf{g} / \mathbf{m g}$ of dried mycelium weight* } \\
\cline { 2 - 5 } & DON & $\boldsymbol{p}^{* *}$ & ZEN & $\boldsymbol{p}$ \\
\hline 0.0 & $0.16 \pm 0.04$ & 0.067 & $0.98 \pm 0.19$ & \\
50.0 & $0.12 \pm 0.02$ & & $1.08 \pm 0.17$ & \\
\hline
\end{tabular}

*Mean $\pm S D$ of three independent cultivation experiments, three replications per treatment in each. ${ }^{* *}$ The differences of treatments from the control (Thymol, 0.0 ppm) are insignificant ( $p>0.05)$.

nystatin (FICI $=0.17)$ used against a zoophilic yeast Malassezia pachydermatis (Schlemmer et al., 2019).

Previously, we found thymol synergistically augmented in vitro ability of three fungicidal formulations to inhibit the growth of fungal colonies (Dzhavakhiya et al., 2012). In this research, enhanced antifungal activity was shown for Dividend ${ }^{\circledR}$ toward B. sorokiniana and $P$. nodorum, Folicur ${ }^{\circledR}$ against Alternaria alternata, and a strobilurin fungicide, Quadris ${ }^{\circledR}$, against B. sorokiniana, Phoma glomerata, and P. nodorum. The current work, reported here, represents a next stage of our investigations involving seed and foliar treatments of barley and wheat with Dividend ${ }^{\circledR}$ or Folicur ${ }^{\circledR}$ combined with thymol to improve suppression of B. sorokiniana and F. culmorum, or $P$. nodorum, commonly controlled by difenoconazole and/or tebuconazole containing fungicides (State Catalogue of Pesticides and Agrochemicals, 2018). These fungi belong to the most destructive seed-born and leaf-associated pathogens of cereals (Bhathal et al., 2003; Shcherbakova et al., 2018) and cause a number of economically significant diseases, such as wheat and barley common root (B. sorokiniana) and Fusarium crown-footroot rot, head blight (F. culmorum), and glume/leaf blotch of wheat ( $P$. nodorum).

At certain concentrations, thymol is known to be phytotoxic and was reported to inhibit seed germination and growth of some weed plants (Kordali et al., 2008; Araniti et al., 2020). However, in our study we preliminarily determined DMSO-dissolved thymol concentrations for use in chemosensitization which did not negatively affect seed germination, or cause lesions on wheat leaves, and only marginally prevented pathogen development (Tables 1, 3). In parallel, fungicide dosages of Dividend ${ }^{\circledR}$ and Folicur $^{\circledR}$, selected for our experiments to show sensitization by thymol, were at levels that did not protect seedlings or only provided a minor protective effect, and were far lower than dosages recommended for agricultural use (Tables 1, 4, 5). Results obtained using co-applications of thymol with Dividend ${ }^{\circledR}$ on naturally infected barley grain and artificially inoculated wheat seeds, as well as results of foliar treatments of wheat seedlings with Folicur ${ }^{\circledR}$ combined with thymol, showed this redox-active plant metabolite significantly improved the protective effects of difenoconazole and tebuconazole. In all cases, the combined treatments resulted in significantly more effective suppression of plant diseases than the application of the fungicide alone (Figures 1, 3). Moreover, compositions of tested fungicides and the sensitizer provided the same effective protection as Dividend ${ }^{\circledR}$, alone, or Folicur ${ }^{\circledR}$, alone, if these fungicides were applied at 10 or 2.5 times higher dosages, respectively (Figures 1, 3). The fact that Er values significantly exceeded Ee values showed this efficacy was synergistically enhanced by chemosensitization of the pathogens to both triazoles. The one exception was reduction of disease severity as an additive effect of difenoconazole and thymol against F. culmorum. Although in two of four performed assays, co-application of thymol and Dividend ${ }^{\circledR}$ on barley seeds did not enhance the protective effect against Alternaria root rot, a high efficacy of thymolcombined Dividend/01 toward the predominant B. sorokiniana provided the same reduction of incidence of common root rot as the fungicide alone at its highest dosage (Dividend/1) in all experiments.

Currently, a general concept explaining augmentation of pathogen sensitivity to antifungal agents co-applied with a sensitizing compound is based on the sensitizing compound and fungicide attacking different pathways of fungal metabolism or different stages of the same metabolic pathway. This concept seems to be quite reasonable to explain a possible mechanism underlying enhanced fungicidal effects demonstrated in our experiments. Indeed, for various natural sensitizers, destabilizing structural integrity of cellular and vacuolar membranes, induction of oxidative stress via ROS generation with the added provocation of osmotic stress, are main mechanisms augmenting sensitivity of fungi to triazoles and other antimycotics (Campbell et al., 2012). Although all potential mechanisms of thymol activity against plant pathogenic fungi are, so far, poorly understood, its antimicrobial effect has been reported to be mainly associated with extensive damage of fungal membranes. This effect is due to the thymol hydroxyl group binding to spore and hypha membranes and lipid peroxidation impairing ergosterol biosynthesis in fungal cells (Ahmad et al., 2011; De Lira Mota et al., 2012; Gao et al., 2016). Like other redox-active compounds with sensitizing activity, thymol causes oxidative and osmotic stress responses. For instance, it induces ROS, and then NO generation in A. flavus resulting in lysis and death of fungal spores (Shen et al., 2016). It is also hypothesized that, in some plant pathogens, MAPK signaling associated with reactions to the above-mentioned stresses (Campbell et al., 2012) can be modulated by thymol (Gao et al., 2016). Simultaneously, thymol and triazoles affect different targets. In contrast to thymol, difenoconazole and tebuconazole inhibit $14 \alpha$-demethylase (CYP51) required for cytochrome P450-dependent oxidative demethylation of 24methylene-24,25-dihydrolanosterol, a precursor of ergosterol (FRAC, 2020). Such multiple targeting of fungal metabolism can significantly weaken plant pathogens, enhancing their sensitivity to thymol and fungicidal doses ineffective alone, and thus elevate the suppressive effect of triazoles.

It is possible that mitigation of disease symptoms on detached wheat leaves inoculated with a tebuconazole-tolerant $P$. nodorum mutant was provided by synergy between the fungicide and thymol. Results obtained using detached leaf assays showed thymol can be co-applied with Folicur ${ }^{\circledR}$ to suppress development of a resistant pathogen in plant tissues at the same fungicidal dose inhibiting a sensitive wild strain. These findings warrant further investigations on sensitization of sensitive and resistant 


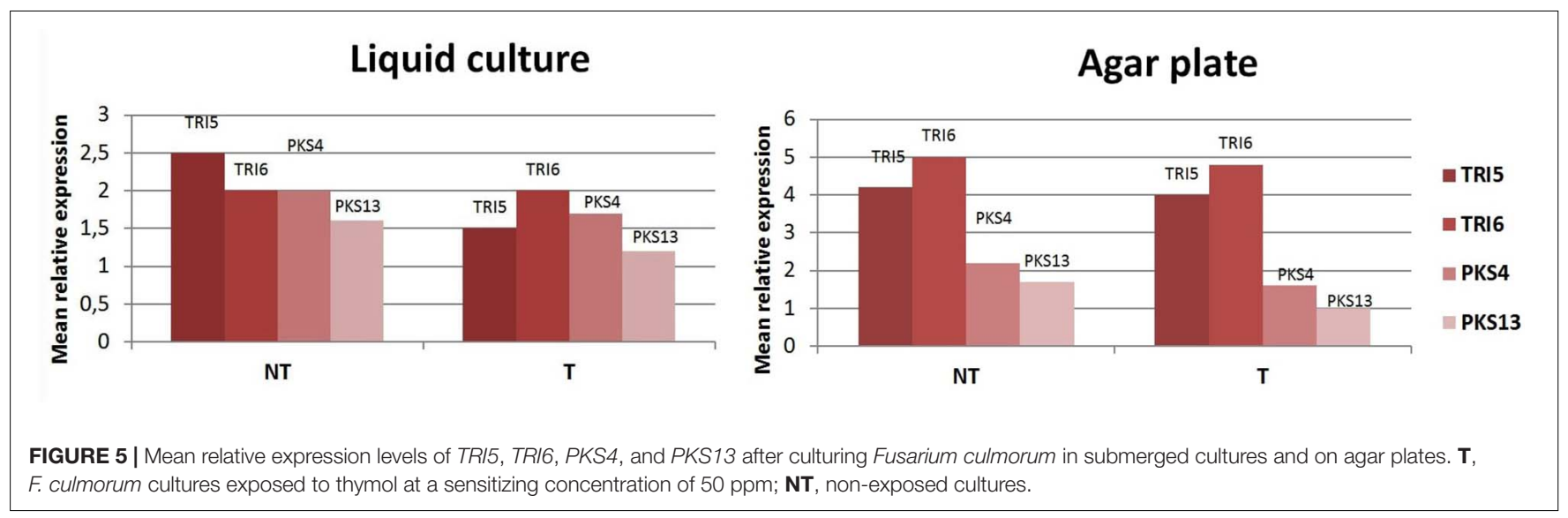

P. nodorum strains under expanded assay conditions, such as greenhouse or field experiments.

Interestingly, in this study, thymol concentration enhancing the sensitivity of both $B$. sorokiniana and $P$. nodorum in seed and seedling treatments, respectively, exceeded in vitro sensitizing dose selected in prior experiments (Dzhavakhiya et al., 2012) using dilutions based on checkerboard assays (Odds, 2003). Hence, vegetation experiments are necessary as the first step in validating if sensitization discovered in vitro reflects augmentation of antifungal effects on plants in the field.

Some redox-active compounds including thymol, which induce oxidative stress, were reported to activate the biosynthesis of polyketide mycotoxins in Aspergillus spp. (Kim et al., 2015; Roze et al., 2015; Dzhavakhiya et al., 2016) and trichothecene production in some Fusarium species (Gardiner et al., 2010). Taking this into account, we cultured a DON- and ZEAproducing $F$. culmorum strain in the presence of thymol at $50 \mathrm{ppm}$, the same concentration used for seed treatments to improve the effect of lowered Dividend dosages. In these experiments, we evaluated production levels of both mycotoxins in the cultural liquor and expression of genes participating in mycotoxigenesis. Results showed that treatment of fungal cultures by thymol did not boost DON- and ZEA production, and did not up-regulate key toxin biosynthetic genes (Table 6 and Figure 5). In the case of gene TRI5, encoding trichodiene synthase, and genes PKS4 and PKS13, encoding polyketide synthases, the expression levels were slightly lower after thymol treatment. Expression levels of TRI6, a gene encoding a global transcription regulator, were the same in both treated and nontreated cultures. These results suggest thymol, at the sensitizing concentration, does not potentiate expression of genes associated with the biosynthesis of the test fusarial toxins and their subsequent production.

In conclusion, this research showed promise for applying thymol to improve fungicidal efficacy of difenoconazole and tebuconazole against cereal root rot and glume/leaf blotch agents, including fungicide-resistant mutants. Importantly, the same concentration of this sensitizer may be used in both seed and foliar treatments against different cereal pathogens. However, further research is necessary to confirm if the thymoltriazole co-applications will result in sensitization of seed- and leaf-associated plant pathogenic fungi or regulation of mycotoxin production under field conditions. Additional investigations are also needed to determine if thymol affects expression of other toxigenesis-related genes in other Fusarium root rot agents.

\section{DATA AVAILABILITY STATEMENT}

The primers and fluorogenic probes were designed based on the alignment of the following sequences retrieved from GenBank (https://www.ncbi.nlm.nih.gov/nucleotide/): U22464, AY130290, MN313473-313507 (TRI5); MH514940-514957, MH001614MH001648 (TRI5 and TRI6); AY429625, XM009259983 (PKS4), AY495638, JF966273 (PKS13); DQ019316 (PKS4 and PKS13); KY205745-205748, DQ382164-382166 (TEF1a).

\section{AUTHOR CONTRIBUTIONS}

LS and VD conceived the concept of the research and designed the experiments. OM, LA, and DE performed the main experiments, prepared the reagents, materials, and analysis tools. AS performed the experiments on expression of genes associated with mycotoxigenesis. LS and AS wrote the original draft and prepared the figures and tables. LS, VD, and SZ reviewed and edited the drafts of the manuscript. All authors reviewed and approved the manuscript.

\section{FUNDING}

This study was supported by the Russian Science Foundation (project 18-16-00084).

\section{ACKNOWLEDGMENTS}

We acknowledge Tatyana M. Voinova, Senior Researcher of ARRIP Laboratory of Molecular Biology for kind provision of a tebuconazole-tolerant $P$. nodorum strain used in this research. We thank Bruce Campbell, USDA ARS Western Regional Research Center (retired), for kind assistance with the manuscript proofreading and additional editing. 


\section{REFERENCES}

Ahmad, A., Khan, A., Akhtar, F., Yousuf, S., Xess, I., Khan, L. A., et al. (2011). Fungicidal activity of thymol and carvacrol by disrupting ergosterol biosynthesis and membrane integrity against Candida. Eur. J. Clin. Microbiol. Infect. Dis. 30, 41-50. doi: 10.1007/s10096-010-1050-8

Ait Dra, L., Brahim, M., Boualy, B., Aghraz, A., Barakate, M., Oubaassine, S., et al. (2017). Chemical composition, antioxidant and evidence antimicrobial synergistic effects of Periploca laevigata essential oil with conventional antibiotics. Ind. Crops Prod. 109, 746-752. doi: 10.1016/j.indcrop.2017.09.028

Aksoy, C. S., Avci, F. G., Ugurel, O. M., Atas, B., Sayar, N. A., and Akbulut, B. S. (2020). Potentiating the activity of berberine for Staphylococcus aureus in a combinatorial treatment with thymol. Microb. Pathog. 149:104542. doi: 10.1016/j.micpath.2020.104542

Araniti, F., Miras-Moreno, B., Lucini, L., Landi, M., and Abenavoli, M. R. (2020). Metabolomic, proteomic and physiological insights into the potential mode of action of thymol, a phytotoxic natural monoterpenoid phenol. Plant Physiol. Biochem. 153, 141-153. doi: 10.1016/j.plaphy.2020. 05.008

Belozerskaya, T. A., and Gessler, N. N. (2007). Reactive oxygen species and the strategy of antioxidant defense in fungi: a review. Appl. Biochem. Microbiol. 43, 506-515. doi: 10.1134/S0003683807050031

Bhathal, J., Loughman, R., and Speijers, J. (2003). Yield reduction in wheat in relation to leaf disease from yellow (tan) spot and Septoria nodorum blotch. Eur. J. Plant Pathol. 109, 435-443. doi: 10.1023/A:1024277420773

Campbell, B. C., Chan, K. L., and Kim, J. H. (2012). Chemosensitization as a means to augment commercial antifungal agents. Front. Microbiol. 3:79. doi: 10.3389/fmicb.2012.00079

Castillo, S., Pérez-Alfonso, C. O., Martínez-Romero, D., Guillén, F., Serrano, M., and Valero, D. (2014). The essential oils thymol and carvacrol applied in the packing lines avoid lemon spoilage and maintain quality during storage. Food Control 35, 132-136. doi: 10.1016/j.foodcont.2013.06.052

De Lira Mota, K. S., de Oliveira Pereira, F., de Oliveira, W. A., Lima, I. O., and de Oliveira Lima, E. (2012). Antifungal activity of Thymus vulgaris L. essential oil and its constituent phytochemicals against Rhizopus oryzae: interaction with ergosterol. Molecules 17, 14418-14433. doi: 10.3390/molecules171214418

de Oliveira, M. S., Almeida, M. M., Salazar, M., de, L. A. R., Pires, F. C. S., Bezerra, F. W. F., et al. (2018). "Potential of medicinal use of essential oils from aromatic plants," in Potential of Essential Oils, ed. H. El-Shemy (London: InTech), 1-21.

Dzhavakhiya, V., Shcherbakova, L., Semina, Y., Zhemchuzhina, N., and Campbell, B. (2012). Chemosensitization of plant pathogenic fungi to agricultural fungicides. Front. Microbiol. 3:87. doi: 10.3389/fmicb.2012.00087

Dzhavakhiya, V. G., Voinova, T. M., Popletaeva, S. B., Statsyuk, N. V., Limantseva, L. A., and Shcherbakova, L. A. (2016). Effect of various compounds blocking the colony pigmentation on the aflatoxin B1 production by Aspergillus flavus. Toxins 8:11. doi: 10.1006/EXCR.2002.5662

El-Marasy, S. A., El Awdan, S. A., Hassan, A., and Abdallah, H. M. I. (2020). Cardioprotective effect of thymol against adrenaline-induced myocardial injury in rats. Heliyon 6:e04431. doi: 10.1016/j.heliyon.2020.e04431

FRAC (2020). FRAC Code List (c). Available online at: https://www.frac.info/ docs/default-source/publications/frac-code-list/frac-code-list-2020-finalb16c2 b2c512362eb9a1eff00004acf5d.pdf?sfvrsn=54f499a_2 (accessed January 17, 2021).

Gao, T., Zhou, H., Zhou, W., Hu, L., Chen, J., and Shi, Z. (2016). The fungicidal activity of thymol against Fusarium graminearum via inducing lipid peroxidation and disrupting ergosterol biosynthesis. Molecules 21:770. doi: 10 . 3390/molecules21060770

Gardiner, D. M., Kazan, K., Praud, S., Torney, F. J., Rusu, A., and Manners, J. M. (2010). Early activation of wheat polyamine biosynthesis during Fusarium head blight implicates putrescine as an inducer of trichothecene mycotoxin production. BMC Plant Biol. 10:298-302. doi: 10.1186/1471-2229-10-289

González-Aguilar, G., Ansorena, M., Viacava, G., Roura, S., and Ayala-Zavala, J. (2013). "Plant essential oils as antifungal treatments on the postharvest of fruit and vegetables," in Antifungal Metabolites from Plants, eds M. RazzaghiAbyaneh and M. Rai (Berlin: Springer), 429-446.

Greenhalgh, R., Blackwell, B. A., Savard, M., Miller, J. D., and Taylor, A. (1988). Secondary metabolites produced by Fusarium sporotrichioides DAOM165006 in liquid culture. Agric. Food Chem. 36, 216-219. doi: 10.1021/jf00079a054
Guarda, A., Rubilar, J. F., Miltz, J., and Galotto, M. J. (2011). The antimicrobial activity of microencapsulated thymol and carvacrol. Int. J. Food Microbiol. 146, 144-150. doi: 10.1016/j.ijfoodmicro.2011.02.011

Jacob, C. (2014). Redox active natural products and their interaction with cellular signaling pathways. Molecules 19, 19588-19593. doi: 10.3390/ molecules191219588

James, W. S. (1971). An illustrated series of assessment keys for plant diseases, their preparation and usage. Canadian Plant Dis. Survey 51, 36-65.

Ji, D., Chen, T., Ma, D., Liu, J., Xu, Y., and Tian, S. (2018). Inhibitory effects of methyl thujate on mycelial growth of Botrytis cinerea and possible mechanisms. Postharvest Biol. Technol. 142, 46-54. doi: 10.1016/j.postharvbio.2018. 04.003

Ji, H., Kim, H., Beuchat, L. R., and Ryu, J. H. (2019). Synergistic antimicrobial activities of essential oil vapours against Penicillium corylophilum on a laboratory medium and beef jerky. Int. J. Food Microbiol. 291, 104-110. doi: 10.1016/j.ijfoodmicro.2018.11.023

Kartashov, M. I., Shcherbakova, L. A., Statsyuk, N. V., and Dzhavakhiya, V. G. (2019). Co-application of difenoconazole with thymol results in suppression of a Parastagonospora nodorum mutant strain resistant to this triazole. KnE Life Sci. 4, 1097-1106. doi: 10.18502/kls.v4i14.570

Kim, H. K., and Yun, S. H. (2011). Evaluation of potential reference genes for quantitative RT-PCR analysis in Fusarium graminearum under different culture conditions. Plant Pathol. J. 27, 301-309. doi: 10.5423/PPJ.2011.27.4.301

Kim, J., Chan, K. L., Cheng, L. W., Tell, L. A., Byrne, B. A., Clothier, K., et al. (2019). High efficiency drug repurposing design for new antifungal agents. Methods Protoc. 2:31. doi: 10.3390/mps2020031

Kim, J. H., Chan, K. L., Faria, N. G., and Campbell, B. C. (2012). Targeting the oxidative stress response system of fungi with safe, redox-potent chemosensitizing agents. Front. Microbiol. 3:88. doi: 10.3389/fmicb.2012.00088

Kim, J. H., Chan, K. L., and Mahoney, N. E. (2015). Augmenting the activity of monoterpenoid phenols against fungal pathogens using 2-hydroxy-4methoxybenzaldehyde that target cell wall integrity. Int. J. Mol. Sci. 16, 2685026870. doi: 10.3390/ijms161125988

Kim, J. H., Mahoney, N. E., Chan, K. L., Campbell, B. C., Haff, R. P., and Stanker, L. H. (2014). Use of benzoanologs to enhance antimycotic activity of kresoxim methyl for control of aflatoxigenic fungal pathogens. Front. Microbiol. 5:87. doi: 10.3389/fmicb.2014.00087

Kim, K., Lee, Y., Ha, A., Kim, J. I., Park, A. R., Yu, N. H., et al. (2017). Chemosensitization of Fusarium graminearum to chemical fungicides using cyclic lipopeptides produced by Bacillus amyloliquefaciens strain JCK-12. Front Plant Sci. 8:2010. doi: 10.3389/fpls.2017.02010

Kimura, M., Tokai, T., Takahashi-Ando, N., Ohsato, S., and Fujimura, M. (2007). Molecular and genetic studies of Fusarium trichothecene biosynthesis: pathways, genes, and regulation. Biosci. Biotechnol. Biochem. 71, 2105-2123. doi: $10.1271 /$ bbb.70183

Kissels, W., Wu, X., and Santos, R. R. (2017). Short communication: interaction of the isomers carvacrol and thymol with the antibiotics doxycycline and tilmicosin: in vitro effects against pathogenic bacteria commonly found in the respiratory tract of calves. J. Dairy Sci. 100, 970-974. doi: 10.3168/jds.201611536

Kordali, S., Cakir, A., Ozer, H., Cakmakci, R., Kesdek, M., and Mete, E. (2008). Antifungal, phytotoxic and insecticidal properties of essential oil isolated from Turkish Origanum acutidens and its three components, carvacrol, thymol and p-cymene. Bioresour. Technol. 99, 8788-8795. doi: 10.1016/j.biortech.2008.04. 048

Lysøe, E., Klemsdal, S. S., Bone, K. R., Frandsen, R. J. N., Johansen, T., Thrane, U., et al. (2006). The PKS4 gene of Fusarium graminearum is essential for zearalenone production. Appl. Environ. Microbiol. 72, 3924-3932. doi: 10.1128/ AEM.00963-05

Ma, D., Cui, X., Zhang, Z., Li, B., Xu, Y., Tian, S., et al. (2019). Honokiol suppresses mycelial growth and reduces virulence of Botrytis cinerea by inducing autophagic activities and apoptosis. Food Microbiol. 88:103411. doi: 10.1016/j.fm.2019.103411

Marchese, A., Orhan, I. E., Daglia, M., Barbieri, R., Di Lorenzo, A., Nabavi, S. F., et al. (2016). Antibacterial and antifungal activities of thymol: a brief review of the literature. Food Chem. 210, 402-414. doi: 10.1016/j.foodchem.2016. 04.111 
Najafloo, R., Behyari, M., Imani, R., and Nour, S. (2020). A mini-review of thymol incorporated materials: applications in antibacterial wound dressing. J. Drug Deliv. Sci. Technol. 60:101904. doi: 10.1016/j.jddst.2020.101904

Navarro, D., Diaz-Mula, H. M., Guillen, F., Zapata, P. J., Castillo, S., Serrano, M., et al. (2011). Reduction of nectarine decay caused by Rhizopus stolonifer, Botrytis cinerea and Penicillium digitatum with Aloe vera gel alone or with the addition of thymol. Int. J. Food Microbiol. 151, 241-246. doi: 10.1016/j. ijfoodmicro.2011.09.009

Odds, F. C. (2003). Synergy, antagonism, and what the chequerboard puts between them. J. Antimicrob. Chemother. 52:1. doi: 10.1093/jac/dkg301

Oktyabrsky, O. N., and Smirnova, G. V. (2007). Redox regulation of cellular functions. Biochemistry (Moscow) 72, 132-145. doi: 10.1134/ S0006297907020022

Park, J.-H., Jeon, Y.-J., Lee, C.-H., Chung, N., and Lee, H.-S. (2017). Insecticidal toxicities of carvacrol and thymol derived from Thymus vulgaris Lin. against Pochazia shantungensis Chou \& Lu., newly recorded pest. Sci. Rep. 7:40902.

Porter, J. A., and Monu, E. A. (2019). Evaluating the antimicrobial efficacy of white mustard essential oil alone and in combination with thymol and carvacrol against Salmonella. J. Food Prot. 82, 2038-2043. doi: 10.4315/0362-028X.JFP19-029

Richer, D. L. (1987). Synergism: a patent view. Pest Manag. Sci. 19, 309-315. doi: $10.1002 /$ ps.2780190408

Riella, K. R., Marinho, R. R., Santos, J. S., Pereira-Filho, R. N., Cardoso, J. C., Albuquerque-Junior, R. L. C., et al. (2012). Anti-inflammatory and cicatrizing activities of thymol, a monoterpene of the essential oil from Lippia gracilis, in rodents. J. Ethnopharmacol. 143, 656-663. doi: 10.1016/j.jep.2012.07.028

Rosato, A., Carocci, A., Catalano, A., Clodoveo, M. L., Franchini, C., Corbo, F., et al. (2018). Elucidation of the synergistic action of Mentha piperita essential oil with common antimicrobials. PLoS One. 13:e0200902. doi: 10.1371/journal. pone.0200902

Roze, L. V., Laivenieks, M., Hong, S. Y., Wee, J., Wong, S. S., Vanos, B., et al. (2015). Aflatoxin biosynthesis is a novel source of reactive oxygen species - a potential redox signal to initiate resistance to oxidative stress? Toxins. 7, 1411-1430. doi: 10.3390/toxins7051411

Sanin, S. S., and Sanina, A. A. (2013). Septoria Leaf Blotch and Stagonospora Leaf/Glume Blotch of Wheat: Diagnostics, Phytosanitary Observations, and Plant Protection Managing. Moscow: AMA Press.

Schlemmer, K., Jesus, F. P., Tondolo, J. S., Weiblen, C., Azevedo, M., Machado, V., et al. (2019). In vitro activity of carvacrol, cinnamaldehyde and thymol combined with antifungals against Malassezia pachydermatis. J. Mycol. Med. 29, 375-377. doi: 10.1016/j.mycmed.2019.08.003

Shagdarova, B. T., Ilyina, A. V., Lopatin, S. A., Varlamov, V. P., Kartashov, M. I., and Arslanova, L. R. (2018). Study of the protective activity of chitosan hydrolyzate against Septoria leaf blotch of wheat and brown spot of tobacco. Appl. Biochem. Microbiol. 54, 71-75. doi: 10.1134/S0003683818010118

Shcherbakova, L. A., Nazarova, T. A., Mikityuk, O. D., Istomina, E. A., and Odintsova, T. I. (2018). An extract purified from the mycelium of a tomato wiltcontrolling strain of Fusarium sambucinum can protect wheat against Fusarium and common root rots. Pathogens 7:61. doi: 10.3390/pathogens7030061
Shcherbakova, L. A., Syomina, Y. V., Arslanova, L. R., Nazarova, T. A., and Dzhavakhiya, V. G. (2019). Metabolites secreted by a nonpathogenic Fusarium sambucinum inhabiting wheat rhizosphere enhance fungicidal effect of some triazoles against Parastagonospora nodorum. AIP Conf. Proc. 2063:030018. doi: 10.1063/1.5087326

Shen, Q., Zhou, W., Li, H., Hu, L., and Mo, H. (2016). ROS involves the fungicidal actions of thymol against spores of Aspergillus flavus via the induction of nitric oxide. PLoS One 11:e0155647. doi: 10.1371/journal.pone.0155647

Stakheev, A. A., Khairulina, D. R., and Zavriev, S. K. (2016). Four-locus phylogeny of Fusarium avenaceum and related species and their species-specific identification based on partial phosphate permease gene sequences. Int. J. Food Microbiol. 225, 27-37. doi: 10.1016/j.ijfoodmicro.2016.02.012

Stakheev, A. A., Samokhvalova, L. V., Mikityuk, O. D., and Zavriev, S. K. (2018). Phylogenetic analysis and molecular typing of trichothecene-producing Fusarium fungi from Russian collections. Acta Naturae 10, 79-92.

State Catalogue of Pesticides and Agrochemicals (2018). State Catalogue of Pesticides and Agrochemicals Approved For the Use in Russian Federation in 2020. Moscow: Ministry of Agriculture of Russian Federation, 325.

Teixeira, B., Marques, A., Ramos, C., Neng, N. R., Nogueira, J. M. F., Saraiva, J. A., et al. (2013). Chemical composition and antibacterial and antioxidant properties of commercial essential oils. Ind. Crops Prod. 43, 587-595. doi: 10. 1016/j.indcrop.2012.07.069

Veras, H. N. H., Rodrigues, F. F. G., Botelho, M. A., Menezes, I. R. A., Coutinho, H. D. M., and Costa, J. G. M. (2017). Enhancement of aminoglycosides and $\beta$-lactams antibiotic activity by essential oil of Lippia sidoides Cham. and the thymol. Arab. J. Chem. 10, S2790-S2795.

Villafana, R. T., Ramdass, A. C., and Rampersar, S. N. (2019). Selection of Fusarium trichothecene toxin genes for molecular detection depends on TRI gene cluster organization and gene function. Toxins 11:36. doi: 10.3390/toxins110 10036

Zadoks, J. C., Chang, T. T., and Konzak, C. F. (1974). A decimal code for the growth of cereals. Weed Res. 14, 415-421. doi: 10.1111/j.1365-3180.1974.tb 01084.x

Zhang, Z., Qin, G., Li, B., and Tian, S. (2015). Effect of cinnamic acid for controlling gray mold on table grape and its possible mechanisms of action. Curr. Microbiol. 71, 396-402. doi: 10.1007/s00284-015-0863-1

Conflict of Interest: The authors declare that the research was conducted in the absence of any commercial or financial relationships that could be construed as a potential conflict of interest.

Copyright (C) 2021 Shcherbakova, Mikityuk, Arslanova, Stakheev, Erokhin, Zavriev and Dzhavakhiya. This is an open-access article distributed under the terms of the Creative Commons Attribution License (CC BY). The use, distribution or reproduction in other forums is permitted, provided the original author(s) and the copyright owner(s) are credited and that the original publication in this journal is cited, in accordance with accepted academic practice. No use, distribution or reproduction is permitted which does not comply with these terms. 